\title{
MULHERES EM MOVIMENTO: O FEMINISMO NO BRASIL
}

\author{
Jaqueline Teodoro Comin iD 1
}

\section{Resumo}

Este artigo consiste na análise da trajetória do movimento feminista no Brasil enquanto movimento político, à linha de frente na conquista de direitos, na luta pela democracia e igualdade. O objetivo é analisar historicamente a partir das três ondas que marcam a evolução do movimento, pautas e garantias de direitos, principalmente na constituição de 1988 e tantas outras leis no código civil brasileiro que foram aportes para mudança social. A metodologia é baseada em uma revisão bibliográfica acerca do tema. Os resultados apontam para importância do movimento para toda sociedade, na manutenção e garantia de direitos, bem como seu potencial de transformação cultural, social e política.

Palavras-chave: Mulheres; Movimento, Feminismo; Direitos.

\section{WOMEN ON THE MOVE: FEMINISM IN BRAZIL}

\section{Abstract}

This article consists of an analysis of the trajectory of the feminist movement in Brazil as a political movement, at the forefront in the conquest of rights, in the struggle for democracy and equality. The objective is to analyze historically from the three waves that ma the evolution of the movement, guidelines and guarantees of rights, mainly in the 1988 constitution and so many other laws in the Brazilian civil code that were contributions to social change. The methodology is based on a bibliographic the theme fence. The result point to the importance of the movement for the whole society, in the maintenance and guarantee of rights, as well as its potential for cultural, social and political transformation.

Keywords: Women; Movement; Feminism; Rights.

\section{Introdução}

Este artigo visa discutir a trajetória do movimento feminista no Brasil ${ }^{2}$ enquanto movimento político, histórico, fundamental na conquista de direitos, na luta pela democracia e igualdade em um país com altos índices de desigualdade.

O objetivo consiste em percorrer a história do movimento no âmbito nacional, focando em sua importância na conquista de direitos, como sua participação essencial na conquista de direitos no processo da constituinte de 1988 e tantas outras leis no código civil que são aportes para mudança social e cultural.

\footnotetext{
${ }^{1}$ Mestre em Sociologia pela Universidade Federal da Grande Dourados. Licenciada em Ciências Sociais pela Universidade Federal de Mato Grosso do Sul em 2017. Agente de pesquisa do IBGE.

${ }^{2} \mathrm{O}$ artigo tem é um recorte da dissertação de mestrado da autora, intitulada "Mulheres e política institucional em Mato Grosso do Sul: a relação entre o social e o constitucional". UFGD, 2019.
} 
O texto está dividido em três partes, sendo que a primeira apresenta análises do movimento feminista brasileiro e seu desenvolvimento no decorrer da história, especialmente nas lutas pautadas pelas três grandes ondas deste movimento, compreendendo em que sentido propôs avanços nas pautas encaminhadas pelas mulheres, cunhando conceitos e encaminhamentos para suprimir as diferenças sociais.

A segunda parte trata da participação ampla das mulheres no processo de elaboração da constituição de 1988, ampliado a cidadania, democracia, políticas públicas. Desta maneira, impulsionaram mudanças jurídicas em relação à participação/atuação das mulheres em contextos diversos, especialmente no campo político institucional, espaço de maior visibilidade e de relações de poder, e com predomínio masculino.

A terceira parte da continuidade ao movimento feminista em sua importância política e na conquista de direitos, analisando a lei como aporte de mudanças práticas, especialmente com as mudanças no código cível de 2002.

A metodologia utilizada é baseada em uma pesquisa bibliográfica a cerca da história do movimento. É de suma importância compreender a história do movimento feminista, sua atuação política, principalmente enquanto propulsor da transformação social, cultural e conquista de direitos.

As conquistas promovidas com as demandas feministas, no contexto social e introduzidas no Estado como garantias, foram encaminhadas por mulheres conscientes da dominação histórica, criando resistências e construindo demandas para sua superação.

Desta maneira, podemos compreender o caráter histórico, político e cultural dos lugares ocupados pelas mulheres e suas atuações enquanto agentes de mudança social, cultural e das estruturas de poder.

\section{O feminismo brasileiro: algumas considerações acerca da atuação do movimento}

O feminismo é um movimento social ${ }^{1}$ e político que evidenciou as relações de poder como uma de suas principais afirmações. "O sexo é político"; slogan criado

\footnotetext{
${ }^{1}$ A organização enquanto movimento data o século XIX, com o advento da sociedade e transformações culturais, sociais e políticas adquiridas com a revolução francesa, as mulheres começam a se organizar com base na consciência da desigualdade presente entre homens e mulheres e passam a questionar os padrões sociais existentes, lutando pela igualdade e garantia de direitos. A partir daí surgem as sufragistas que lutaram pelo direito ao voto no Reino Unido e EUA, no final do século XVIII até as primeiras décadas do século XIX, os principais nomes desta luta são Mary Wollstonecraft e Emmeline Pankhurst, a primeira escreveu o livro "Em Defesa dos Direitos da Mulher", no qual contesta as ideias de Rousseau sobre as diferenças "naturais" entre homens e mulheres e a superioridade masculina na capacidade de raciocínio. Antes disso, Olympe Gouges escreveu sobre os direitos das mulheres durante a revolução francesa, com a "Declaração dos Direitos da Mulher e da Cidadã" (guilhotinada em 1793 acusada de querer ser um homem de Estado, esquecendo as 'virtudes' de seu sexo) e Sojourner Truth lutou em defesa do abolicionismo e pelos direitos das mulheres, o seu discurso "Ain't I a women?, onde fala sobre a escravidão, invisibilidade da mulher negra na sociedade, suas dores, vivências e anseio por igualdade. Esses são marcos do movimento feminista enquanto organização, mas muitas mulheres lutaram ao longo da história, a desigualdade entre mulheres e homens data há milênios, como na Grécia onde as mulheres eram excluídas das discussões políticas, na Idade Média com a Inquisição e a caça as bruxas, na qual milhares foram mortas, queimadas, decapitadas, até se unirem e organizarem enquanto movimento pelo fim da desigualdade, assim, é um movimento político em seu cerne e atua diretamente na sociedade pela garantia de direitos.
} 
pela jornalista e ativista Carol Hanish, publicado em manifesto em 1970, contesta as argumentações de que o feminismo tratava de questões do âmbito privado/doméstico e que estas não seriam públicas.

Este marco desmistificou a política partidária/institucional como algo inerente apenas ao espaço público, evidenciando a relação entre os espaços, e em seu caráter opressivo, que transpassa todas as relações, implicando na distribuição de poder, dos espaços, funções, economia, de maneira centrada no masculino.

Ao afirmar que o sexo é político, pois contém também ele relações de poder, o feminismo rompe com os modelos políticos tradicionais, que atribuem uma neutralidade ao espaço individual e que definem como política unicamente a esfera pública, "objetiva ". Desta forma, o discurso feminista, ao apontar para o caráter também subjetivo da opressão, e para os aspectos emocionais da consciência, revela os laços existentes entre as relações interpessoais e a organização política pública. (PITANGUY, 1985, p. 08).

Nessa lógica, o feminismo busca equidade para atuação de homens e mulheres, onde ambos possam ter capacidades amplas, como seres humanos e não segregados em estereótipos masculinos e femininos que taxam, moldam, podam, distribuem, regulam. Como afirma Rosa Luxemburgo, "por um mundo onde sejamos socialmente iguais, humanamente diferentes e totalmente livres".

No Brasil o movimento feminista surge com as sufragistas, pela conquista de direitos políticos, fase intitulada "primeira onda", com início no final do século XIX, e maior expressão a partir de 1910, quando foi fundado o Partido Republicano. Essa primeira fase defendia a inclusão das mulheres na política e nos espaços públicos, mas, como mostra Pinto (2003), não questionava os motivos das desigualdades e por isso ficou conhecido como um movimento intra-classes, liderada por mulheres brancas da elite, e que apenas tangenciavam o questionamento do sistema patriarcal de dominação e opressão. A ênfase esteve na reivindicação do direito a participação política institucionalizada.

Assim, o movimento feminista da década de 1920, e que teve como principal expoente Bertha Lutz, liderou as ações em prol da participação feminina na política, enquanto candidatas e eleitoras:

A luta pelo direito do voto da mulher chegou ao seu fim em 1932, quando "novo Código Eleitoral" incluiu a mulher como detentora do direito de votar e de ser votada. Mas a FBPF não diminuiu suas atividades nos primeiros anos da década de 1930: tentou, sem sucesso, eleger Bertha Lutz para a Constituinte de 1934; pressionou parlamentares para incluírem na Constituição novos direitos para a mulher; promoveu uma convenção nacional na Bahia, que pretendeu dar nova estrutura hierárquica e burocrática à federação com o objetivo de transformála organização nacional (PINTO, 2003, p. 28).

A Federação Brasileira pelo Progresso Feminino (FBPF) foi uma organização que lutava pelos direitos das mulheres, fundada em 1922 no Rio de Janeiro, sendo Bertha Lutz uma das precursoras. Esta continuou em busca de ocupar uma representação politica, o que ocorreu somente em 1936, após o falecimento de um deputado, onde ela assumiu como suplente, contudo com o golpe de 1937 o movimento reduziu sua força. 
A partir de 1946, com a redemocratização, as ideias influenciadoras mundiais, como também no Brasil, em torno do socialismo, logo foram sufocadas pela ditadura militar da década de 1960 (e que se estendeu até meados de 1980, com a redemocratização), este período marca a "segunda onda" do movimento feminista, onde se dinamizou e expandiu demandas para as mulheres, envoltas a saúde, educação, creches, aborto, igualdade salarial e melhores condições, trabalhistas, medidas para conter a violência contra a mulher e melhores serviços públicos no geral.

A segunda onda vem com a redemocratização no pós-Vargas a partir da década de 1950, e vai até final dos anos oitenta, tendo em 1960 a comercialização da pílula anticoncepcional como uma das principais marcas, que revolucionou a sexualidade feminina e a dinâmica procriação x prazer feminino, direitos reprodutivos, liberdade sexual, sendo também o auge do movimento estudantil, hippie, e a identificação da opressão com o lema "o pessoal é político". O debate se concentrou em torno das múltiplas opressões que as mulheres sofriam, e que as levou a se unirem e se perceberem enquanto coletividade capaz de provocar mudanças na sociedade.

O marco daquele período foi a publicação da obra "O segundo Sexo", da francesa Simone Beauvoir, servindo de inspiração para o feminismo mundial na década de 1960, com reflexões dos aspectos psicológicos e culturais sobre as mulheres e na construção da subjetividade do feminino, surge os estudos das mulheres, posteriormente o conceito de gênero que engloba pesquisas com esta temática. No Brasil os estudos de gênero aparecem no cenário final de 1980 para início da década de 90.

A expressão "não se nasce mulher, torna-se mulher", de Simone de Beauvoir, foi expressivo para o feminismo, a qual explica a "feminilidade" como um estado de ser construído socialmente, culturalmente e historicamente, uma posição social que estabelece diferenças e molda as mulheres em seus modos de ser, agir e estar.

Este foi um referencial para o desenvolvimento do feminismo acadêmico no Brasil daquele momento, sendo uma das maiores expressões Heleieth Saffioti, com a defesa de sua tese em 1967: "Mulher na Sociedade de Classes: Mito e Realidade", publicada em 1969, é um marco por trazer a cena a opressão das mulheres com perspectiva de classes, raça e gênero.

Foi também uma fase configurada pela explosão de diversos movimentos sociais das minorias, na luta pela discriminação racial, ampliando o campo de atuação política, evidenciando as desigualdades sociais, para além do econômico, vinculado à classe, raça-etnia e gênero, desvelando as formas de dominação e exercício do poder. Assim, aquele período, inspirado na revolução socialista do leste europeu, o movimento mundial teve uma nova fase, questionando o conservadorismo social, as relações de poder e sua distribuição nos espaços, sob os efeitos da obra de Beauvoir, publicada na década anterior.

No Brasil o contexto do golpe militar de 1964 freou o movimento e deixou um rastro de repressão, censura, torturas, exílios, mortes, etc. Neste cenário se acentuou o sufocamento de direitos humanos e manifestações sociais, onde as condições para a organização de qualquer movimento acarretava consequências perigosas e até letais. "Tínhamos, portanto, na Europa e nos Estados Unidos, cenários de grande efervescência política, de revolução de costumes, de radical renovação cultural, enquanto no Brasil o clima era de ditadura militar, repressão e morte" (PINTO, 2003, p. 43). 
Outra configuração aliada ao movimento feminista foi aquela das mulheres de classes médias populares, as quais "[...] a partir da própria condição de donas-decasa, esposas e mães, intervinham no mundo público. São exemplos dessas organizações os movimentos contra a carestia, os clubes de mães, o movimento Pela anistia, entre muitos outros" (PINTO, 2003, p. 43).

Eram grupos concentrados, na maioria, em São Paulo e Rio de Janeiro, e não havia uma contabilidade de quantos os constituíam, reunindo mulheres conhecidas entre si, as quais refletiam informalmente sobre suas condições sociais. Mas era uma organização de caráter privado, e para se tornar um membro, haveria de vir por convite pessoal ${ }^{1}$.

O movimento feminista, no caso brasileiro, alcançou maior organização a partir da década de 1970, mesmo em meio ao AI-5 do regime militar, com repressões e mortes. Isso ocorreu por meio da criação dos grupos de trabalho nas universidades, com pesquisas e debates sobre o tema, bem como movimentos de cunho popular, parte deles conduzidos pela Igreja Católica, como as CEBs, outros pelos sindicatos, pautando demandas, por reinvindicações de direitos para as mulheres, como: funções iguais, salários, direitos, igualdade de oportunidades, aprimoramento profissional, sexualidade, creches, saúde, acesso às universidades, alcançando maior formação com a educação superior.

Os estudos de gênero contribuíram para amplo debate e aprofundamento da realidade das mulheres em sociedade, sendo desenvolvidas pesquisas com temas como: desigualdade salarial, direitos reprodutivos, estereótipos feminino e masculino, violência doméstica, divisão do trabalho, espaços públicos e privados inter-relacionados, distribuição do poder, racismo, homofobia e ódio ao feminino, política, economia, o papel das mulheres indígenas nas comunidades, entre outros. Estes temas formaram base para análises, conscientização, avanços, transformação cultural, de costumes, deslocamento das posições sociais das mulheres, desenvolvimento de políticas públicas, e que colocaram as mulheres no centro do debate.

A ampliação do debate ocorreu também a partir de obras marcantes deste contexto: A mística Feminina, de Betty Friedman (1963), Política Sexual, de Kate Millett (1969), as quais impulsionaram o debate, os movimentos, mobilizou as mulheres em cena, trazendo á luz a história ocultada, a luta das mulheres, as condições e os espaços ocupados, tornando visível a estrutura e modelos que oprimem e hierarquizam.

A concepção do gênero, defendida pelo movimento feminista, como teoria de análise nega o determinismo biológico, imposto como natural, revelando o caráter cultural do sexo enquanto marcador, diferenciador, atribuidor de sentido, enfatizando sua produção e arranjo social engendrado nas e pelas estruturas sociais. É acima de tudo uma ferramenta política que desnuda as diferenças baseadas no sexo, as instituições, os discursos, símbolos, as ferramentas e redes de poder que hierarquizam e fabricam sujeitos.

Em 1975 o movimento feminista brasileiro, passou a figurar fora das reuniões privadas, organizadas anteriormente, que ocorriam no período do governo do general

${ }^{1}$ Era o período da ditadura militar e da perseguição dos movimentos sociais que questionassem a lógica estatal. A maneira encontrada para manter a organização, esteve no diálogo direto e privado. 
Geisel, devido às repressões e crueldades praticadas com aporte do AI-5, o qual só termina a partir dos anos 1980. No cenário mundial a ONU (Organização das Nações Unidas) foi fundamental, pois definiu o ano de 1975 como o ano Internacional da Mulher e a década da mesma, realizando uma conferência sobre o tema no México. Foi uma etapa de formalização do movimento, desenvolvendo rumo à institucionalização.

Nesse período ocorreu o Congresso denominado de "O Papel e o Comportamento da Mulher na Realidade Brasileira", no Rio de Janeiro, resultando na formação do Centro de Desenvolvimento da Mulher Brasileira ${ }^{1}$. E no ano seguinte (1979) foi criada a Sociedade Brasileira para o Progresso da Ciência (SBPC), marcando o feminismo acadêmico nacional, desenvolvendo as pesquisas científicas referentes à situação das mulheres em âmbito nacional.

Vale frisar que a maior parte da segunda onda feminista no Brasil que aqui estamos nos referindo ocorreu durante o período militar, onde as mulheres tiveram fundamental importância política enquanto movimento de oposição, resistindo, lutando e pressionando aquele regime, durante o qual muitas foram perseguidas, violentadas e mortas pelo estado.

A partir de 1979, com o fim do AI-5, inicia-se o processo de redemocratização que perdurou por quase uma década. Durante os anos 1980 ocorreu a anistia aos presos políticos exilados no exterior desde 1960, trazendo de volta militantes e figuras importantes dos movimentos. Além disso, havia em curso também a reforma partidária, o que acarretou maior liberação, menos medo e mais manifestações.

Essas mudanças e a reforma trouxe espaço para os movimentos oprimidos buscar por representatividade, e consequentemente o fortalecimento do movimento feminista, ampliando suas demandas, buscando conter a violência contra as mulheres, bem como a construção de políticas públicas na área da saúde. No campo político houve a inserção das mulheres na esfera institucional por meio de Conselhos da Condição da Mulher e Delegacias da Mulher, além do maior número de candidatas envolvidas no processo político institucional e social.

O período da redemocratização, em meados da década de 1980 , até a transição para os anos de 1990, foi marcado pelo surgimento e efervescência da "terceira onda" do movimento feminista, dando novas linhas nos debates, nas lutas, nos espaços de atuação para além da categoria gênero. É a fase dos estudos póscoloniais, numa pluralidade do movimento e dos feminismos que o constituíam, sendo as mulheres uma categoria diversa, composta, atravessada por classe, raçaetnia, interseccionalidade, a teoria Queer, entre outras pautas que emergem neste contexto.

${ }^{1}$ PROPOSTA DE CRIAÇÃO DO CENTRO DE DESENVOLVIMENTO DA MULHER BRASILEIRA:

Propomos a criação de um centro de Desenvolvimento da Mulher Brasileira que obedecerá à seguinte estrutura:

a) um centro de estudo, reflexão, pesquisa e análise;

b) um departamento de ação comunitária para tratar concretamente e em nível local dos problemas da mulher.

O objetivo principal do centro será combater a alienação da mulher em todas as camadas sociais para que ela possa exercer o seu papel insubstituível e até agora não assumido no processo de desenvolvimento. A nossa primeira etapa de ação será a aquisição de uma sede, personalidade jurídica, estatutos e o apoio do maior número de mulheres a quem pedimos filiação. Decidimos pela criação de um jornal que terá como objetivo a veiculação e a divulgação dos problemas reais da mulher no sentido de criar uma consciência nacional de sua condição (PINTO, 2003, p. 58).

Perspectivas em Diálogo, Naviraí, v. 8, n. 16, p. 273-295, jan./abr. 2021. 
No cenário brasileiro foi criado o Conselho Nacional dos Direitos da Mulher, no ano de 1985, em conjunto com a campanha das Diretas-Já, correlacionado ao Ministério da Justiça, com orçamento próprio Este Conselho atuou de 1985 a 1989, sendo desativado pelo governo de Collor, e, posteriormente, tornado secretaria, por meio da medida provisória no 103, de 2003, passando a colocar pautas feministas no espaço público.

Esta atuação do movimento feminista caracterizou uma etapa em que se expressou à formalização do movimento e se instituiu uma nova fase, passando a ser público, como também se desenvolveu para institucionalização, através do desenvolvimento dos estudos sobre as condições de mulheres, estudos de gênero por meio do feminismo acadêmico, criaram as delegacias das mulheres, políticas públicas de saúde, organizações políticas e de pesquisas, como o Cfemea, de expressão nacional, entre outros. Dessa forma, Avelar (2015) comenta:

[...] principais redes de articulação das plataformas, feministas: a Articulação das Mulheres Brasileiras (AMB), a Marcha Mundial das Mulheres (MMM) e a União Brasileira de Mulheres UBM). São organizações formal e jurídica atente estabelecidas em todo o território nacional. [...] Os trabalhos de mobilização, articulação e representação dessa ONG giram em torno de quatro temas: " Poder e Política", "Enfrentamento à Violência de Gênero", "Direitos Sexuais e Reprodutivos" ,"Trabalho e Proteção Social" [...] Do lado do Estado, as agências de política para as mulheres são, entre outras, o Conselho Nacional do Direitos da Mulher, fundado em 1985, ligado ao Ministério da Justiça, e a Secretaria dos Direitos das Mulheres (Sedim), fundada em 2002, sob o governo Fernando Henrique Cardoso. No governo Lula foram criadas a Secretaria de Políticas para Mulheres (SPM) e a Secretaria de Política para Promoção da Igualdade Racial (Seppir), ambas com status de Ministério. (AVELAR, 2015, p.214-215).

No entanto, a atuação das mulheres na política institucional a partir daquele período foi sendo alargada, em relação às décadas anteriores. Uma participação marcante foi na Assembleia Constituinte de 1988, onde o CNDM foi essencial, promovendo campanhas nacionais com o slogan "Constituinte pra valer tem que ter direitos da mulher!", e também organizou em conjunto com mulheres feministas, de associações, grupos de bairros, produzindo a "Carta das Mulheres", compartilhada pelo país como "carta-modelo", destinada as mulheres, que essas escrevessem para os constituintes suas principais demandas, assim como elaborou emendas, e esteve junto à bancada feminina na Câmara:

Através da atuação de grupos autônomos e ONGs de mulheres e da atuação dinâmica do Conselho Nacional dos Direitos da Mulher - CNDM, órgão vinculado à Presidência da República, criado em 1985 por pressão e com a colaboração do movimento de mulheres, foi possível articular o chamado "lobby do batom". Com essa designação descrevia-se a ação dos grupos de mulheres no sentido de sensibilizar os constituintes para incorporarem as propostas de novos direitos - como os direitos reprodutivos - e não contaminarem a nova Constituição com o conteúdo discriminatório da legislação ordinária, no tocante às relações de gênero. (BARSTED, 1994, p. 253).

Além dessa organização institucional, a grande expressividade se deu por associações de bairros, coletivos feministas, que escreveram a carta aos constituintes reinvindincando direitos democráticos, de igualdade e serviços públicos de qualidade, a qual representou um importante documento público do movimento feminista 
contemporâneo no Brasil e foi direcionado a interesses não só das mulheres, mas em prol da justiça social, defendendo o Sistema Único de Saúde, o ensino público, a reforma agrária e tributária, além dos direitos específicos em relação às mulheres, como a saúde, o poder sobre o próprio corpo, direitos de propriedade, sociedade conjugal etc. Outro assunto fundamental presente na carta foi sobre violência contra a mulher, defendendo a "integridade física e psíquica das mulheres, redefinindo o conceito de estupro e sua classificação penal, apenando o explorador sexual e solicitando a criação de delegacias especializadas no atendimento da mulher em todos os municípios do território nacional" (PINTO, 2003, p. 75).

As emendas apresentadas foram diversas, as que traziam maior número de assinaturas, foram recolhidas por três associações: Federação das Associações de Bairro de Salvador, Associação de Moradores de Plataforma e a Associação de Mulheres de Cosme de Farias. Nela continha propostas sobre a aposentadoria das donas-de-casa, defendendo o caráter do trabalho doméstico enquanto colaboração à renda familiar, dispêndio de tempo das mulheres para outras ocupações, por isso, seria necessária a garantia da aposentadoria.

A emenda 20 foi a mais expressiva, que continha em suas reinvindicações a linguagem inclusiva quando se referia a homens e mulheres, trabalhadoras/res, saúde, igualdade no casamento, uma rede de assistência à mulher vítima de violência, direito a propriedade de terra, a aposentadoria para as mulheres do campo, além da licença maternidade, direitos que até então estavam para as mulheres das cidades, e foram atendidos na Constituição de 1988. Essa ampla conquista de direitos reinvindicados na carta através do movimento e luta de mulheres de todo Brasil, representou um marco histórico, para democracia e para o feminismo, onde $80 \%$ das demandas apresentadas foram inseridas na constituição. ${ }^{1}$

No período pós-constituinte de 1988 , o movimento feminista se constitui em uma nova fase marcada pela prestação de serviços às mulheres vítimas de violência e as organizações não-governamentais (ONGs). ${ }^{2}$ E nesta nova configuração da

${ }^{1}$ Os direitos da mulher na constituição de 1988 :

-"homens e mulheres são iguais em direitos e obrigações, nos termos desta Constituição";

-"às presidiárias serão asseguradas condições para que possam permanecer com seus filhos durante o período de amamentação";

-"licença à gestante, sem prejuízo do emprego e do salário com duração prevista de cento e vinte dias";

-"licença paternidade, nos termos fixados em lei";

-"proteção do mercado de trabalho da mulher, mediante incentivos específicos nos termos da lei";

-"proibição de diferença de salários, de exercício de funções e de critério de admissão por motivo de sexo, idade, cor ou estado civil";

-"são assegurados à categoria dos trabalhadores domésticos [..., sua integração na previdência social";

-"o título de domínio e a concessão de uso serão conferidos ao homem ou à mulher, ou a ambos, independentemente do estado civil, nos termos e condições previstos em lei";

-"os direitos e deveres referentes à sociedade conjugal são exercidos pelo homem e pela mulher";

-"fundado nos princípios da dignidade da pessoa humana e da paternidade responsável, o planejamento familiar é livre decisão do casal, competindo ao Estado propiciar recursos educacionais e científicos para o exercício desse direito, vedada qualquer forma coercitiva por parte de instituições oficiais ou privadas" (PINTO, 2003, P.78).

2 Posteriormente, nas primeiras décadas do século XXI, com o objetivo de combater a violência contra as mulheres, criou-se a Lei $11.340 / 2016$, publicada em 07/08/2006, conhecida como Lei Maria da Penha, que desencadeou uma série de outras medidas, dentre elas a criação das Casas Abrigo da Mulher, destinadas às vítimas de violência doméstica, oferecendo apoio médico, jurídico e psicológico 
situação das mulheres, são englobados temas como a maternidade, prevenção do câncer, planejamento familiar, sexualidade e aborto. Estes últimos considerados polêmicos em uma sociedade conservadora, católica e patriarcal, onde o Estado regula a sexualidade das mulheres, ainda assim, houve notável o crescimento de políticas públicas principalmente na área da saúde.

Com isso, percebemos a atividade do movimento se especializando em redes de prestação de serviços, enquanto o feminismo se generaliza em suas ideias fundamentais. Os estudos pós-coloniais trouxeram novo fôlego ao debate e definiram os rumos da terceira onda, caracterizando o feminismo pós-moderno a partir de uma nova perspectiva epistemológica, que incorpora múltiplos feminismos com diferentes pautas, conflitos, desassociando a noção universal do que é ser mulher e da questão da desigualdade. É a fase da pluralidade, diversidade, intersseccionalidade, múltiplas realidades e o reconhecimento da diferença (sexualidade, raça-etnia, geração, classe), questionando a construção da mulher universal ${ }^{1}$, e os interesses e representações atrás dessa criação, dando ênfase as tensões das relações de poder.

Jacques Derrida² também argumenta sobre o jogo das dicotonomias, a qual nós aprendemos a pensar em uma lógica polarizada em extremos opostos, marcando a superioridade de um e inferioridade do outro. Este modo de organizar mantém a estrutura desigual como tal:

Desconstruir a polaridade rígida dos gêneros, então, significaria problematizar tanto a oposição entre eles quanto a unidade interna de cada um. Implicaria observar que o pólo masculino contém o feminino (de modo desviado, postergado, reprimido) e vice-versa; implicaria também perceber que cada um desses pólos é internamente fragmentado e dividido (afinal não existe a mulher, mas várias e diferentes mulheres que não são idênticas entre si, que podem ou não ser solidárias, cúmplices ou opositoras) (Louro, 2003, p.31-32).

A meta é deslocar o que está fixo, tido como natural, desconstruir esse modelo de pensamento polarizado e hierárquico. Essa lógica dicotômica que atua na diferença é a mesma que impõe esse padrão do que é referência do normal/padrão e o que marca a distinção e legitima esta estrutura. Perturbar a ideia enraizada de dominante-dominado, fora do caráter heterossexual normativo, para além dessa caixa, rumo às diversas feminilidades e masculinidades entrecruzadas, as quais constroem resistência e fazem exercícios de poder.

Com isso o conceito de gênero foi problematizado no sentido do uso político deste conceito, surgindo novas perspectivas, coexistindo com a base dos estudos de gênero, mas compreendendo as mulheres enquanto sujeitos políticos, percebendo as relações enquanto mutáveis, diversas e oriundas de contextos múltiplos. Pensar quem define a diferença e quem é considerado diferente é o caminho para compreender os interesses e relações de poder neste jogo que institui desigualdades.

de conscientização das causas da violência, clínicas de saúde e sexualidade voltada às mulheres, sosviolência. As mulheres são reconhecidas enquanto vítimas e portadoras de direitos dados pelos órgãos públicos, o que é um grande avanço dado que anteriormente essa violência dizia respeito ao espaço privado e a cada homem perpetrador dela.

${ }^{1}$ Ver material do IPEA "Os Dilemas da Construção do Sujeito no Feminismo da Pós-Modernidade". Acesso: http://repositorio.ipea.gov.br/bitstream/11058/6864/1/TD_2210.pdf.

2 DERRIDA, J. A Escritura e a Diferença. Trad. Maria Beatriz Marques Nizza da Silva. São Paulo: Perspectiva, 2002.

(1) (1) Perspectivas em Diálogo, Naviraí, v. 8, n. 16, p. 273-295, jan./abr. 2021. 
Reivindicar as diferenças como é feito pelos feminismos nessa fase do movimento, não quer dizer abandonar o desejo de igualdade, já que este é um conceito político interligado a diferença. O que esta em pauta é o reconhecimento das diferenças enquanto constituintes de individualidades subjetivas e trajetórias distintas, e a igualdade refere à equivalência de direitos, oportunidade, acesso e ocupação de espaços. Portanto, há o reconhecimento de distintas lutas, pautas, necessidades e anseios, pensar essas em um único núcleo é negar outros marcadores de diferença, os quais possuem condições históricas diversas, em cada sociedade, cultura, grupo e que organiza os sujeitos em diferentes níveis.

Na etapa atual Judith Butlher ${ }^{1}$ desenvolve a teoria Queer, apresentando a ideia de que gênero e sexo são intercambiáveis e o sistema binário constitui modelos que mantêm divisões, conformando os sujeitos em apenas duas opções possíveis (homem e mulher). Segundo essa ideia impõe-se uma heteronormatividade, criando os sujeitos nesta lógica e os representando a partir dessas identidades fixas. Assim: "[...] a produção disciplinar de gênero produz estabilizações falsas para os interesses da construção heterossexual e a regulação da sexualidade dentro do domínio reprodutivo" (Piscitelli, 2001, p. 15).

Butler questiona e problematiza as categorias sexo, gênero e desejo enquanto modelos discursivos normatizadores e apresenta uma proposta de subverter as identidades para além dos modelos existentes unificadores que reproduz opressões, sobre a qual se almeja emancipação. Esse padrão, que nos é apresentado socialmente, constituí sujeitos políticos por meio de exclusões, por "[...] atos de diferenciação que o distinguem do seu exterior constitutivo" (Butler, 1998, p. 30).

Isto quer dizer: construir e pensar através desses modelos é o mesmo que manter essa normatividade excludente e legitimar as relações de poder hierarquizadas. Pois, por fim, nesse fazer do movimento, com redes em diferentes culturas, o movimento feminista no Brasil desponta como o mais organizado da América latina ${ }^{2}$, e podemos citar algumas organizações sociais de mulheres em lutas, as quais atuam pressionando o poder público, reivindicando direitos. E na linha de frente, como a Marcha das Mulheres Negras contra o Racismo e a Violência e pelo Bem Viver; Rede de Mulheres Negras na América Latina e Caribe; Marcha das Margaridas (mulheres rurais, do campo e da floresta); Marcha das Vadias; Marcha Mundias de Mulheres; Voz das Mulheres índigenas; Movimento de Mulheres Trabalhadoras Rurais do Nordeste; Frente Nacional Contra a Criminalização das Mulheres e Pela Legalização do Aborto; Articulação Brasileira de Lésbicas; Movimento de Mulheres Camponesas; Rede Nacional Feminista de Saúde, Direitos Sexuais e Direitos Reprodutivos; União Brasileira de Mulheres - UBM, entre tantos outros que estão na luta.

Nas eleições de 2018, como dizemos em nota anterior, as mulheres estiveram organizadas à frente da oposição contra o governo que assumiu em 2019, pelas posições por ele expressadas, com ênfase machista, racista, antidemocrático,

\footnotetext{
${ }^{1}$ BUTLER, Judith. Problemas de gênero. Feminismo e subversão de identidade. Tradução de Renato Aguiar. Rio de Janeiro: Civilização Brasileira, 2010.

Ver artigo: "Pós-feminismo através de Judith Butler"no endereço eletrônicohttp://www.scielo.br/pdf/ref/v14n2/a18v14n2.pdf

2 Ver: https://www.cartacapital.com.br/politica/o-movimento-feminista-no-brasil-e-o-mais-

organizado-da- america-latina/ e Acessar em: https://www.marchamundialdasmulheres.org.br/amarcha/nossa-historia/.
} 
homofóbico e todas as perdas de direito que eles representam. Milhares de mulheres foram para rua marchar por "Ele Não", organizado por ativistas, feministas, mulheres partidárias e não partidárias protestando contra essa onda fascista e em defesa da democracia. O desrespeito para com as mulheres foi imensurável e apresentado pelo candidato sob a linha da "Ideologia de Gênero", a qual o então presidenciável visava combater toda a discussão sobre sexualidade e diferenças de gêneros. Com isso, ele negava o fazer das mulheres e a dominação que historicamente foi nutrida no tecido social brasileiro.

O contexto citado suscitou no movimento feminista, e mesmo nas mulheres que dele não faziam parte, a necessidade de resistência à opressão, levando-as a criar uma corrente de contestação e recusa ao pensamento do referido candidato, pautando a revolta pelas ruas das cidades brasileiras, e negando a candidatura do mesmo com o lema: "ELE NÃO".

O movimento feminino foi iniciado na rede social, especialmente pelas páginas do Facebook, What's up, Twitter, movimentando grande número de mulheres em grupos, e culminando com a ocupação de daquelas com pequeno número de habitantes e também de estrangeiras, como Londres, Paris e Lisboa. Nas grandes cidades brasileiras, agigantando-se, em São Paulo, Rio de Janeiro, Recife, dentre outras. Contestavam a visão estereotipada do candidato, que remetia a colonização/dominação de corpos femininos. Para além do resultado do pleito, a mobilização colocou o protagonismo das mulheres em evidência, assumindo posições no cenário brasileiro, ainda marcado pelo machismo e pelo poder patriarcal.

Ademais nos últimos dias, no dia 08 de maço de 2019, pelo terceiro ano seguinte, o feminismo internacional se organizou em uma mobilização global intitulada "Para além do 8 de março: rumo a uma 'Internacional Feminista'"1, com atos espalhados por todo mundo, Espanha, Itália, Argentina, Brasil, Chile, México, França, de maneira transnacionais, anticoloniais, antirracistas e anticapitalistas contra as forças reacionárias dos governos de direita que atacam as minorias e democracia. Além disso, o movimento feminista vem participando e influenciando no âmbito institucional por meio de Conselhos, conferências, movimento, redes, ONGs, comissões e secretarias, atuando na agenda pública e na conquista direta dos direitos das mulheres. A seguir alguns exemplos de organizações políticas de mulheres:

Para se ter ideia do sucesso da representação das organizações de mulheres, o Cfemea, ONG feminista e braço legislativo da Articulação das Mulheres Brasileiras, uma das mais importantes do país, analisou as leis federais aprovadas desde 1888, quando ocorreu legalmente o fim da escravidão, e constatou que, no que tange aos direitos das mulheres, das 249 leis aprovadas, duzentas o foram após a Constituinte de 1988, um marco na mobilização das mulheres na política brasileira [...] a legislação avançou na criminalização da violência doméstica e do assédio sexual; no seguro-saúde para a reconstrução de mamas em caso de câncer; em licença- maternidade; em inovações no Código Civil quanto à igualdade de homens e mulheres no casamento; na eliminação do pátrio poder; no seguro-desemprego para trabalhadoras domésticas; no âmbito do Sistema Único de Saúde (SUS); em leis que dispõem obre a efetivação de ações que assegurem a prevenção, a detecção, o tratamento e o seguimento dos cânceres de colo uterino e de mama; e na assistência jurídica para as mulheres com situação de prisão (AVELAR, 2015, p.212-213).

${ }^{1}$ Acessar em: https://www.internacionalfeminista.org/.

Perspectivas em Diálogo, Naviraí, v. 8, n. 16, p. 273-295, jan./abr. 2021. 
Ainda podemos citar a participação das mulheres por meio de três principais redes de organização feminista: a Articulação das Mulheres Brasileiras (AMB), a Marcha Mundial das Mulheres (MMM), e a União Brasileira de Mulheres (UBM). "São organizações formal e jurídica estabelecidas em todo o território nacional [...]" (AVELAR, 2015, p.214). Essas organizações atuam sobre temas como: poder e política, enfrentamento da violência de gênero, trabalho e direitos sexuais das mulheres.

Desta maneira, vemos o caminho percorrido pelas mulheres em constante luta através do movimento feminista e também fora dele, produzindo avanços, mas indicando que apenas a lei no papel não transforma uma realidade cultural impregnada pelo patriarcado e subordinação das mulheres. Esta deve vir acompanhada de políticas públicas efetivas, promovidas pelo estado, e que visem transformar concepções culturais que hierarquizam os sexos.

Desta maneira, percebemos que o feminismo é necessário como força propulsora de transformações com este sentido, para que ocorra a democracia, garantindo o reconhecimento dos direitos humanos, da igualdade e dos direitos das mulheres.

\section{Mulheres se fazendo e refazendo na política: o marco da constituinte de 1988}

O Brasil em seu processo político foi liderado por uma elite seleta, senhores de engenho, coronéis, sendo rompido, supostamente com Vargas, o qual também era um coronel a favor dos empresários. Porém, logo instaurou a ditadura, encurtando o espaço do debate, anulando organizações sociais, em 1937 até 1945 e depois em 1964 , até a redemocratização em 1984. Nesse contexto nossa democracia é extremamente recente, caminhando a passos curtos e conservadores ${ }^{1}$.

Cabe destacar que a redemocratização, em 1985, ampliou a força do movimento feminista, já iniciada na declaração da ONU22, em 1975, quando demarcou

\footnotetext{
${ }^{1}$ A conquista do voto para as mulheres - importante neste processo - foi obtida, como destacamos anteriormente, pela ação das sufragistas que lutaram e reivindicaram seus direitos, conseguindo com a nova Constituição de 1934, "[...] elaborada por uma Assembleia Nacional Constituinte, eleita pelo voto popular, [que] ratificou essa faculdade, tornando-a dever apenas quando a mulher exercesse função pública remunerada" (BARSTED, 1994, p.246). Em 1937, o Estado Novo de Vargas garantiu direitos na área do trabalho, e as mulheres e crianças conseguiram obter proteção legal, a partir da década de 1930. Em 1943, foram reconhecidos os direitos de todos os trabalhadores/as, com a criação da CLT: mulheres, menores de idade e homens, passaram a ter a jornada de trabalho de 8 horas, descanso no final de semana, carteira de trabalho, entre outras conquistas.

2 Cabe destacar que em 1948 houve a Declaração Universal dos Direitos Humanos, elaborada pelas Nações Unidas, visando que os documentos fossem norteadores das constituições dos países para serem elaboradas sob a perspectiva de gênero. O movimento internacional de proteção dos direitos humanos, no âmbito das mulheres, esteve concentrado em temas como a discriminação contra as mulheres, violências e direitos sexuais e reprodutivos. Ainda assim, mesmo diante dos questionamentos para com as diferenças sociais e suscitando o encaminhamento de legislações, ocorreu recusa, configurada no aumento de discriminações, violências físicas, mortalidade materna, sub-representação política, diferenças no mercado de trabalho, menos salários, violência doméstica, o que demonstra o quanto é intensa a discriminação de gênero e a mudança de postura, "[...] essa discriminação é "naturalizada" pela sociedade e permeia as ações do Estado. (BARSTED, 1994, p.238). Com o regime militar, em 1967 o Brasil teve nova Constituição, período o qual a ONU decretou como a década da mulher, ação efetivada em 1975. Esta organização, a ONU, foi originada pós a segunda 
aquele período como a década internacional da mulher. No Brasil foi criado o Conselho Nacional dos direitos da Mulher (CNDM), o qual foi fundamental na evolução dos direitos e a ampliação da atuação política das mulheres pelos movimentos sociais, organizações e política partidária. No mesmo ano foram criadas as Delegacias Especializadas de Atendimento as Mulheres Vítimas de Violências, como mencionado anteriormente.

A criação da CNDM em, 1985, de que falamos anteriormente, teve como objetivo promover políticas com intuito de eliminar a discriminação contra as mulheres e ampliar a participação destas nos espaços públicos. Este foi organizado em comissões de trabalho, em diferentes áreas, como: saúde, educação, violência, creche, legislação, constituinte, cultura e trabalho, atuando como espaço de interlocução com a sociedade, os grupos e movimentos a fim de formular, monitorar e avaliar políticas públicas que visem eliminar as desigualdades e discriminações construídas por razões históricas e culturais.

As redes feministas AMB, UMB e MMM, articularam-se horizontal e verticalmente para a criação do Conselho Nacional dos Direitos da Mulher (CNDM), na instituição da Secretaria de Politicas para Mulheres (SPM) [...] 0 Conselho Nacional de Direitos das Mulheres é o principal espaço institucional de participação da Articulação de Mulheres Brasileiras no governo federal, [...] (AVELAR, 2015, p. 215).

Este momento é um marco histórico, pois o conselho participou ativamente na organização da Carta da Constituinte, formando comissões de advogadas para avaliar os anteprojetos, elaborar emendas, acompanhar e assessorar a bancada feminina, defendendo os direitos das mulheres. Posteriormente serviu de apoio a Secretaria de Políticas Para as Mulheres, a qual também acabou sendo dissolvida quando do golpe de 2015 e a Saída de Presidente Dilma:

\footnotetext{
Das reivindicações gerais constavam: anistia ampla, geral, irrestrita; eleições livres e diretas para todos os cargos eletivos; Assembléia Geral Constituinte, soberanamente eleita; fim da carestia. Nas reivindicações específicas lia-se: criação de creches nas empresas e principalmente nos bairros; aumento do número de áreas de lazer, principalmente nos bairros pobres; aumento do número de escolas e de horas letivas; ampliação e melhoria da merenda escolar nas escolas públicas; igualdade salarial; condições mais adequadas de trabalho (PINTO, 2003, p. 61).
}

As mulheres que organizaram a carta eram oriundas de diversas classes sociais; dos bairros, das universidades, das fábricas e das periferias das cidades e do campo. Sendo organizados encontros nacionais, regionais e locais, de reflexão e articulação na luta pelos direitos das mulheres, atuaram em conjunto com a bancada feminina na Câmara, e formaram o "Lobby do Batom", fundamental no processo da elaboração da constituinte de 1988.

O Lobby do batom marca uma das principais atuações do movimento feminista

guerra mundial com objetivo de manter a paz entre as nações. Em busca destes preceitos, o progresso rumo à igualdade das mulheres em sociedade faz parte de sua agenda e foi estimulada na década de 1970 por meio de três principais Conferências Internacionais: "México, em 1975; Copenhague, em 1980; e Nairobi, (PIMENTEL, 1987, p.29)." Em relação a este período, foi o Brasil o primeiro a ter uma Constituição, após a Declaração Universal dos Direitos do Homem, garantindo em lei a igualdade a todos, inclusive sem diferenças de sexo. 
brasileiro no campo político. Trata-se de uma atividade de pressão de um grupo organizado por coletivos feministas: articuladoras, trabalhadoras rurais, empregadas domésticas, sindicatos, associações, ativistas, bancada feminina (deputadas), grupo de mulheres sobre o poder público; que se engajaram para levar as pautas sociais e influenciar nas decisões, como na área da saúde, trabalho, violência, ensino público, propriedade privada, direitos conjugais, reforma agrária, entre outros incorporados na carta e garantidos na nova constituição. $80 \%$ das demandas atendidas o que significou uma grande conquista a toda sociedade. Isso significou mulheres fazendo política, mesmo que não estivessem majoritariamente nas representações dos cargos da política. As pautas foram levantadas coletivamente, reunidas em mais de 4.000 cartas vindas de todas as capitais do país, apresentadas na formulação da constituinte.

Temas originais foram abordados na carta e debatidos no espaço público, como a violência contra a mulher, o qual redefine o conceito de estupro e penalidade do crime, o que gerou e evidenciou a necessidade da criação de delegacias especializadas no atendimento da mulher em âmbito nacional. A questão do aborto foi colocada enquanto problema público, de saúde e na carta lê-se o pressuposto de que as mulheres tem o poder de decidir sobre seu próprio corpo, desta maneira, abrindo espaço para o debate posteriormente.

A mais expressiva foi a emenda 20, recebeu 42 mil assinaturas pedindo igualdade de direitos e deveres, em suas reinvindicações mencionavam questões trabalhistas, de saúde, igualdade no casamento, uma rede de assistência à mulher vítima de violência, direito a propriedade de terra, a aposentadoria para as mulheres do campo, licença maternidade, entre outros. No MS. A proposta foi orquestrada pela Rede Mulher, de São Paulo, Serviço de Informação da Mulher, de Mato Grosso do Sul (reuniu cerca de 11.000 assinaturas), e pela entidade SOS Corpo, de Pernambuco.

Os direitos conquistados na constituição de $1988^{1}$ foram amplos e se estenderam nos anos seguintes, um dos principais foi o artigo $5^{\circ} \mathrm{com}$ o princípio da isonomia em que "todos são iguais perante a lei, sem distinção de qualquer natureza, resguardando a todos os cidadãos a inviolabilidade do direito à vida, à liberdade, à igualdade, à segurança, à propriedade. O primeiro inciso desse artigo diz: " homens e mulheres são iguais em direitos e obrigações".

$\mathrm{Na}$ área dos direitos humanos foi proibido a tortura, tratamento desumano ou degradante, garantindo as presidiárias estarem junto com os filhos durante o período de amamentação (art. $5^{\circ}, \mathrm{L}$ ). Racismo foi definido como crime, previsto reclusão e pena inafiançável. Neste sentido, foi proibida a diferença salarial, a admissão e distribuição de atividade por motivo de sexo. Houve a proteção do mercado de trabalho para com a mulher, a licença a gestante foi respaldado sem prejuízo de perder o emprego e o recebimento do salário durante cento e vinte dias após o parto (art. $7^{\circ}, \mathrm{XVIII}$ ), inclui-se a licença paternidade.

A assistência gratuita aos filhos e dependentes até 6 anos em creches e préescolas. As trabalhadoras domésticas foram regularizadas com salários mínimos, proibição da redução do mesmo, $13^{\circ}$ salário, folga semanal, férias anuais remuneradas, licença gestante, aposentadoria, previdência social. Foram efetivadas mudanças no direito familiar, onde o estado criou mecanismos para coibir a violência familiar e ofereceu assistência às vítimas, e os direitos conjugais passaram a ser

${ }^{1}$ http://www.planalto.gov.br/ccivil_03/constituicao/constituicaocompilado.htm. 
igualitários com o novo código civil de 2002, o qual anteriormente era oriundo de 1916.

A mulher passou a ter direito ao título de domínio e à concessão de uso da terra, independente de seu estado civil, tanto na área urbana como rural. A aposentadoria passou a ter as seguintes condições, I - trinta e cinco anos de contribuição, se homem, e trinta anos de contribuição, se mulher; II - sessenta e cinco anos de idade, se homem, e sessenta anos de idade, se mulher, ficando reduzido em cinco anos o limite para os trabalhadores rurais de ambos os sexos, e para os que exerçam suas atividades em regime de economia familiar, nestes incluídos o produtor rural, o garimpeiro e o pescador artesanal (art. 201, §70, I e II).

Cita-se ainda a criação do Estatuto da Criança e do adolescente - ECA (lei 8.069/1990), o qual considera as crianças e jovens como cidadãos de direitos, rompendo com a lógica punitiva anterior do Código de Menores. Também garante punição ao abuso, violência e exploração sexual de jovens e crianças no artigo 227.

São considerados crimes inafiançáveis à prática a tortura, o tráfico ilícito de entorpecentes, terrorismo e os crimes hediondos, dentre esses é incluído o estupro e atentado ao pudor, os quais foram enquadrados pelas leis 8.072/1990 e 8.930/1994).

Na área da saúde no mesmo período há a promoção de políticas públicas até então influenciadas negativamente pela Igreja Católica, podemos citar: a Lei do Planejamento Familiar, a qual prevê esterilização cirúrgica, os contraceptivos e as camisinhas como produtos de política pública; a regulação de aborto em alguns casos como, fetos anencéfalos, quando é fruto de um estupro e se for um risco de vida à mulher.

A lei 9.029/95 proibiu formas de tratamento discriminatório contra as mulheres trabalhadoras, os quais eram utilizados como quesitos de contratação ou permanência na relação de emprego com base em atestados de gravidez, esterilização ou outras práticas do tipo. Outro ganho foi a lei 9.797/1999 que incorporou no SUS como serviço público a cirurgia plástica reparadora de mama para as mulheres em tratamento de câncer que tiveram de mutilar os seios no processo.

Em 1997, a lei 9.0504/1997 reviu a determinação do percentual de cotas partidárias estabelecido em 1995, o qual passa a ser considerado no mínimo $30 \%$ e o máximo $70 \%$ para candidaturas de cada sexo, a mesma só foi concretizada nas eleições de 2012. Essa parte de legislação partidária será analisada no capítulo três, onde analiso lei 12.034/2009 das cotas partidárias.

Em 2001 foi aprovada pela lei 10.317 a gratuidade do exame de DNA para pessoas de baixa renda, para fins de comprovação da paternidade por autoridade judiciária requerida. Além disso, no mesmo ano, por meio da lei 10.224, foi incluído assédio sexual como crime. No MS foi decretado lei (2.214/01) para punir práticas de assédio sexual em ambientes de trabalho por motivos de cargo ou função pública.

Em 2002 foi criada a carteira nacional de saúde da mulher pelo SUS, pela lei 10.516, o que representou grande ganho na área da saúde. No ano seguinte foi criado a Secretaria de Políticas para as Mulheres (SPM), por meio da medida $n^{\circ} 103 / 2003$ fruto da organização dos movimentos feministas reivindicando para colocarem 0 reconhecimento de suas pautas nas políticas do Estado. Desta maneira, o Conselho Nacional dos Direitos da Mulher (CNDM) passa a integrar esta secretaria e dar suporte no desenvolvimento de políticas públicas, ações, pesquisas e levantamento de dados sobre a realidade das mulheres brasileiras. Também foi criada uma secretaria para 
promoção da igualdade racial no mesmo ano.

Sobre a SPM, esta foi uma conquista fundamental para elaboração de políticas públicas, conquista de direitos e promoção da igualdade de gênero, no combate a discriminação e violência contra mulheres, nas políticas do governo, elaborando planos de ação para concretizar socialmente, culturalmente, nos estados, municípios e no âmbito do governo federal. Em 2009, através da lei 12.314, foi tornado ministério, com orçamento próprio e poder para elaborar políticas públicas para questões de gênero. Este órgão funcionou de 2003 a 2015, quando foi dissolvido em outros ministérios.

Em mais de uma década de atuação houve grande avanço, como, por exemplo, contribuiu para a proposta do texto da Lei Maria da Penha em 2006, a garantia do programa Bolsa Família e Minha Casa Minha vida para as mulheres, o PAC, no conjunto de implantação de novas creches, o aumento do número de secretarias e diretorias nos estados e municípios para mulheres, desenvolveu políticas de enfrentamento à violência contra mulheres, promoção da autonomia e distribuição do poder, ampliação do acesso das mulheres aos serviços de justiça, revisão da legislação, entre outras medidas concretizadas.

Esse percurso foi trilhado a partir de 2004 com a primeira Conferência Nacional de Políticas para as Mulheres (1 CNPM), a qual teve a participação de 120.000 mulheres em todo o país e 1.787 delegadas debatendo e colocando as pautas que formularam o I Plano Nacional de Políticas para as Mulheres (I PNPM) ${ }^{1}$.

A $2^{\circ}$ CNPM ocorreu em 2007 e contou com a participação de 200.000 mulheres, dentre essas, 2.800 eram delegadas, as quais em conjunto a partir das discussões geradas elaboraram o II PNPM ${ }^{2}$. A terceira e última conferência realizada antes da dissolução do ministério foi em 2011, com 200.000 participantes e 2.125 delegadas.

O último PNPM ${ }^{3}$ foi organizado em dez capítulos, definindo objetivos metas, linhas de ação: o capítulo 1 dispõe sobre a igualdade no mundo do trabalho e autonomia econômica para mulheres; O capítulo 2 propõe práticas para construção de uma educação igual e cidadã para todos; 03 capítulo trata da saúde das mulheres, direitos sexuais e reprodutivos; 04 capítulo traz o enfrentamento a todas as violências exercidas contra mulheres; O capítulo 5 se refere a ocupação e atuação nos espaços de poder e decisão de maneira igualitária, plural e multirracial; 0 capítulo 6 aborda o desenvolvimento sustentável com equidade econômica e social; O capítulo 7 coloca em pauta as mulheres do campo e floresta, colocando a necessidade do fortalecimento econômico, direito à vida, terras, bens, equipamentos e serviços públicos; O capítulo 8 traz ações para área da cultura, esporte, comunicação e mídia construírem uma cultura igualitária, não discriminatória e estereotipada em relação à gênero; 09 capítulo fortalece práticas para o enfrentamento ao racismo, sexismo e lesbofobia. E último capítulo enfatiza práticas que promovam a igualdade entre mulheres jovens, idosas e com deficiência física.

Pauta fundamental a ser aprofundada devido importância das ações e políticas públicas coincidente com o tema da nossa pesquisa é tratado no capítulo 5 , sobre a ocupação dos espaços de decisão e poder. Assim, o plano menciona a estrutura social que mantêm a sub-representação política, apresentando alguns motivos como:

\footnotetext{
${ }^{1}$ Ver o I PNPM: http://bvsms.saude.gov.br/bvs/publicacoes/pnpm_compacta.pdf.

2 Ver o II PNPM: http://portal.mec.gov.br/dmdocuments/planonacional_politicamulheres.pdf.

3 Ver o II PNPM http://www.compromissoeatitude.org.br/plano-nacional-de-politicas-para-asmulheres-2013- 2015-spm-pr-2013/.
} 
[...] persistência da cultura patriarcal que associa os homens ao espaço público e as mulheres ao espaço privado; o peso do poder econômico no processo eleitoral e o custo crescente das campanhas favorecendo as candidaturas masculinas; o pouco tempo dedicado à ação política pelas mulheres, em grande parte pela sobrecarga de responsabilidades, pelo acúmulo das tarefas domésticas e com o cuidados com as/os filhas/os e com os familiares doentes, bem como com os cuidados dispensados às pessoas com deficiência e às idosas/os, além dos dedicados à vida laboral; e as trajetórias políticas das mulheres, menos consolidadas relativamente às dos homens (Brasília: SPM, 2008, p.116).

Tais tópicos do tema central são levantados e reafirmados ao longo desta pesquisa, conduzidos pelo eixo do sistema patriarcal, que mantêm e legitima as relações desiguais, hierárquicas, a divisão dos espaços públicos e privados. E as consequências decorrentes disso, como a divisão de tarefas e sobrecarga dos afazeres domésticos das mulheres, que, consequentemente, levam uma dupla jornada e dificultando a inserção delas em outras práticas no espaço público.

Outro ponto fundamental é o jogo político que estima o poder econômico, consequentemente estimulando candidatos homens, além do sexismo das funções laborais, desigualdade salarial e pouco acesso às funções de cargo/chefia melhor remuneradas, fatores esses que acarretam em menores condições financeiras para mulheres. Além disso, é recente a presença das mulheres ocupando esses espaços políticos institucionais frente aos homens, dominando esse ambiente a mais tempo aliado ao fato dos partidos preterirem homens nos altos postos legislativos e burlarem as cotas partidárias com candidatas laranjas, tema que será aprofundado mais adiante.

A recente trajetória das mulheres no campo da política brasileira pode ser confirmada quando vemos que somente em 1986 foram eleitas deputadas federais um grupo maior de mulheres. A primeira senadora que exerceu mandato foi em 1990 e a primeira a ocupar o cargo de governadora foi em 1994, ainda hoje poucas mulheres conseguem se elegerem para esse cargo.

Constituído historicamente como um ambiente masculino, o campo político trabalha contra as mulheres (bem como os integrantes de outros grupos em posição de subalternidade), impondo a elas maiores obstáculos para que cheguem às posições de maior prestígio e influência, mesmo depois de terem alcançado cargos por meio do voto. (MIGUEL; BIROLI, 2014, p. 105)

Compreender essa realidade é fundamental para compreender as estruturas que afastam as mulheres do poder e pouco vem sendo alteradas pela via institucional. Em 2007 o Brasil ocupava a 99a posição do ranking de 189 países, referente a equidade de gênero nas Câmaras legislativas, número que caiu em 2016 para $152^{\circ}$ na escala dos países, e hoje está no $134^{\circ}$, figurando as últimas posições. O que nos mostra o quanto falta para igualdade e representação democrática das mulheres ocupando cadeiras no poder executivo e legislativo:

Cabe ressaltar, ainda, que os partidos têm um papel fundamental no sistema político brasileiro na medida em que possibilitam, com exclusividade, o acesso a cargos e mandatos eletivos. Por conseguinte, assumem responsabilidades com o equacionamento dos problemas da realidade brasileira e com a educação política das cidadãs e cidadãos (BRASÍLIA: SPM, 2008, p.117). 
Em vista disso, vale frisar que no Brasil, atualmente (2019), existem 35 partidos $^{1}$, os quais são: MDB, PTD, PDT, PT, DEM, PCdoB, PSB, PSDB, PTC, PSC, PMN, PRP, PPS, PV, AVANTE, PP, PSTU, PCB, PRTB, PHS, PCO, DC, PODE, PSL, PRB, PSOL, PR, PSD, PPL, PATRI, PROS, SOLIDARIEDADE, NOVO, REDE, PMB, dos quais apenas quatro deles tem mulheres na direção do partido, sendo o PMB, com a Suêd Haidar Nogueira, PT com Gleisi Hoffmann, PCdoB com Luciana Barbosa de O. Santos e PODE, com Renata Hellmeister de Abreu. A contradição está no fato de que elas estão em grande ${ }^{2}$ número como filiadas, e estão em maior peso na organização dos movimentos sociais e da população como um todo.

Cabe destacar, ainda, que os objetivos gerais do III PNPM para participação de mulheres nos espaços de poder são garantir a participação igualitária, plural e multirracial por meio de transformações institucionais, legislativas e culturais democráticas e promoção políticas para igualdade. Apresenta, ainda, outros objetivos, dentre eles: apoio da reforma política e revisão/criação de leis para igualdade nos espaços públicos de poder; Promover a participação de mulheres em todas as esferas em proporções étnicas, raciais, de orientação sexual, identidade de gênero, geracionais e mulheres com deficiência; Produzir políticas públicas e órgãos para dar suporte na elaboração, implementação e monitoramento nas regiões; Estimular mulheres a ocupar espaços de decisão em partidos, sindicatos, conselhos, associações, movimentos sociais; Consolidar a participação social na promoção da igualdade de gênero e combate a todas as formas de discriminação.

As metas estipuladas no plano foram: garantir a efetividade da aplicação da Lei no 12.034/2009; Agregar o debate sobre reforma política; Estimular a formação política das mulheres com foco em gênero; Ampliar e observar o número de mulheres nos cargos de direção considerando a proporção das mulheres brancas, negras e indígenas; . Contribuir para o aumento do número de mulheres no legislativo; Alargar organismos de políticas para mulheres em âmbito nacional, principalmente nos estados e capitais do mesmo; Fortalecer conselhos estaduais e regionais que promovam os direitos das mulheres, bem como consolidar o CNDM e a formulação de políticas públicas.

A principal e uma das últimas medidas efetivadas pela SPM fruto da ação " Programa Mulher, Viver sem Violência, foi a criação da Casa da Mulher Brasileira, a qual é um centro de atendimento humanizado e especializado no atendimento as mulheres em situação de violência doméstica, agrupando neste espaço e dando suporte com juizado especial para o atendimento as mulheres, núcleo especializado da promotoria, defensoria pública, delegacia especializada no atendimento a mulher, alojamento, brinquedoteca, apoio psicossocial, e capacitação para a sua autonomia econômica. A primeira casa foi inaugurada em Campo Grande MS, em $2015^{3}$.

Cabe destacar, ainda, outras medidas decorrentes da criação da SPM 2003,

\footnotetext{
1 Ver: http://www.tse.jus.br/partidos/partidos-politicos/registrados-no-tse.

${ }^{2}$ Ver gráficosobre total de filiadospor sexo aos partidos brasileiros

https://www.nexojornal.com.br/grafico/2018/04/02/Os-filiados-aos-partidos-brasileirosg\%C3\%AAnero-idade- e-distribui\%C3\%A7\%C3\%A3o.

3 A maior conquista na área penal foi a lei 11.340/2006, a Lei Maria da Penha, a qual pune e cria medidas de enfrentamento contra violências domésticas sofrida pelas mulheres. Nesse quesito outra lei fundamental foi a 13.104/2015 que instituí o crime feminicídio, quando uma mulher é assassinada pela condição de ser mulher, por ódio, desprezo, sentimento de posse ou perca dele, alimentados por uma sociedade patriarcal, onde as mulheres são vistas como propriedade dos homens.
} 
pela lei 10.714 que regula e insere o crime de abandono, pensão alimentícia e omissão de socorro, o que foi fundamental para as milhares de mães solos garantirem os direitos à seus filhos e os pais que abandonam e não ajudam na criação dos mesmos, nem mesmo com gastos financeiros, poderem ser cobrados perante 0 Estado. Em 2004 foi instituído o Programa Bolsa Família, o qual ofereceu uma quantia básica para subsidiar famílias em situação de extrema pobreza que tenham gestantes, nutrizes, crianças e adolescentes (zero a quinze anos), e foi indispensável para diminuir a pobreza e miséria no país.

Em 2005 a lei 11.108 garantiu a humanização do parto com o direito à presença de um acompanhante durante o parto e no pós-parto no sistema público de saúde. No mesmo ano a lei 11.124 preceitua sobre o Sistema Nacional de Habitação de Interesse Social (SNHIS), determinando prioridade para população de baixa renda, estabelecendo cotas para idosas/os, pessoas com deficiência e famílias chefiadas por mulheres. Além disso, criou o Fundo Nacional de Habitação de Interesse Social (FNHIS) e um conselho gestor. Neste período a lei $11.106^{1}$ revisou a legislação penal em relação aos sentidos atribuídos a palavra "mulher" e retirou a expressão "mulher honesta", o que tinha referência à sexualidade e comportamento impostos socialmente, restringindo o acesso ao direito, dando abertura para julgamentos equivocados e legitimando crimes.

Vale ressaltar, como dissemos anteriormente, SPM foi desmantelada pelos últimos governos, o ex-presidente Michel Temer extinguiu o Ministério das Mulheres, da Igualdade Racial e dos Direitos Humanos (MMIRDH), os quais tinham sido recém criado em uma única secretaria e passou a chamar Ministério da Justiça e Cidadania em 2016. Atualmente, em 2019, o eleito (não pela maioria das mulheres) presidente Jair Bolsonaro criou o Ministério da Mulher, Família e Direitos Humanos, comandado por Damares Alves, caracterizando retrocessos, perda de direitos, reprodução da estrutura patriarcal, desigual, discriminatória, violenta, misógina e machista.

\section{A lei como aporte para mudanças sociais}

A aprovação do novo código civil em 2002, pela lei 10.406, em substituição ao antigo código em vigor desde 1916, suprimiu o caráter discriminatório, patriarcal e reprodutor de violências contra as mulheres, os quais eram embasados pelo Estado no antigo código que garantia relações desiguais no âmbito familiar.

A família descrita no Código era organizada de forma hierárquica, tendo o homem como chefe e a mulher em situação de inferioridade legal. O texto de 1916 privilegiou o ramo paterno em detrimento do materno; exigiu a monogamia; aceitou a anulação do casamento face à não virgindade da mulher; afastou da herança a filha mulher de comportamento "desonesto". O Código também não reconheceu os filhos nascidos fora do casamento. Por esse Código, com o casamento, a mulher perdia sua capacidade civil plena, ou seja, não poderia mais praticar, sem o consentimento do marido, inúmeros atos que praticaria sendo maior de idade e solteira. Deixava de ser civilmente capaz para se tornar "relativamente incapaz". Enfim, esse Código Civil regulava e legitimava a hierarquia de gênero e o lugar subalterno da mulher dentro do casamento civil (PIOVESAN, 2011, p. 79-80).

\footnotetext{
${ }^{1}$ Ver: http://www.cfemea.org.br/index.php/colecao-femea-e-publicacoes/colecao-femea/411numero-178- dezembro-de-2014/4490-25-anos-em-busca-de-igualdade-legislativa.
} 
Além disso, o antigo código restringia a capacidade econômica e autonomia das mulheres, pois legitimava a chefia masculina nas relações conjugais e predomínio do esposo na administração dos bens. Somente 14 anos após a constituinte de 1988, ou seja, em 2002, é que as mulheres foram consideradas iguais nas relações familiares.

Observamos que com o novo Código Civil ${ }^{1}$, em 2002, houve alargamento dos direitos das mulheres e a neutralização de algumas discriminações com base na desigualdade de gênero, contidas na legislação e isso fez com que as mulheres saíssem das "sombras" dos maridos, legitimadas nestas instâncias, como quando determinava que:

[...] ao casar não apenas "assume a condição de companheira, consorte e colaboradora do marido nos encargos de família, cumprindo-lhe velar pela direção material e moral desta" (tal qual previa o art. 240 do Código de 1916), mas passa também a exercer direitos e deveres baseados na comunhão plena de vida e na igualdade entre os cônjuges (ROSTELATO, 2004, p. 145).

O nome dos conjugues ao casarem também passou por alterações, concedendo a ambos os sexos a possibilidade de acrescentarem, ou não, o nome dos companheiros na certidão de casamento. Além disso, a opção de continuarem com nomes de solteiros, fato que não era permitido no antigo Código Cívil de 1916, que legitimava o sentimento de posse e subordinação das mulheres em relação aos homens. Consideramos que era a mulher que acrescia o nome do companheiro em seu nome.

Essa situação fortalecia o sentimento de dependência feminina, a começar pela linguagem, quando de apresentação de determinada mulher, sendo comum ouvir, até a poucas décadas (e mesmo nos dias atuais), a apresentação da mulher pelo viés do companheiro, como: "a Maria, do Roberto Carlos". Nesse exemplo, a Maria existe a partir do Roberto Carlos, o qual denota a identificação dela, pela posse dele.

Ao tratar a respeito do Planejamento Familiar, o Código Civil de 2002 alicerçou a disposição constitucional, ao afirmar que o Planejamento Familiar é livre decisão do casal, além de expressar que é competência do Estado, propiciar recursos educacionais e financeiros para o exercício desse direito; próbe-se também, qualquer tipo de coerção, por parte de instituições privadas ou públicas, não podendo assim, nenhuma instituição determinarás mulheres, quantos filhos ter e quando tê-los, sendo esta, uma decisão exclusiva do casal, é o que se verifica no art. $1565, \S 20$, que dispõe: "(...) § 200 planejamento familiar é de livre decisão do casal, competindo ao Estado propiciar recursos educacionais e financeiros para o exercício desse direito, vedado qualquer tipo de coerção por parte de instituições privadas ou públicas" (ROSTELATO, 2004, p. 146).

Um passo importante foi efetuado em relação à direção da sociedade conjugal, deixando de ser exclusivamente do marido, mas em conjunto do casal, de acordo com os interesses da família como um todo, mantendo o apreço a igualdade. Disposição expressa consta no art. 1.568 do Código Civil de 2002: "Os cônjuges são obrigados a concorrer, na proporção de seus bens e dos rendimentos do trabalho, para o sustento da família e a educação dos filhos, qualquer que seja o regime

${ }^{1}$ Ver o Código Civil na íntegra em: http://www.planalto.gov.br/ccivil_03/leis/2002/L10406.htm. (c) (1)

Perspectivas em Diálogo, Naviraí, v. 8, n. 16, p. 273-295, jan./abr. 2021. 


\section{patrimonial" (ROSTELATO, 2004, p. 146-147).}

Com a ampliação de medidas visando a participação ativa das mulheres nas mais diversas áreas sociais, havendo o acesso ao mundo público, ocorreu, ao mesmo tempo, aumento das violências domésticas ${ }^{1}$, 0 que demonstra o desrespeito $e$ despreparo masculino em lidar com uma sociedade mais igualitária. A participação feminina parece indicar perda de poderes, aos olhos masculinos, e por isso a negação deles diante das resistências femininas.

Decorrente desse fato, entendermos as dificuldades que as mulheres enfrentam para chegarem até as instâncias mais altas do poder, não sendo de fácil acesso a maioria delas, cargos de chefia em grandes empresas, juízas em altas esferas, médicas cirurgiãs, cargos de política institucional, dentre outros espaços. Assim, percebemos que há um abismo entre o constitucional e o social, pelo fato que não basta apenas prescrever em lei, mas aliado a isso fomentar o tecido social, visando mudar práticas e relações sociais.

Por isso, a defesa que aqui apresentamos, é para que ocorra um processo combinado entre legislação e políticas públicas. É uma tentativa educacional que deve ser assumida pelo Estado, enquanto garantidor de direitos humanos, atuando na mudança de hábitos naturalizados que suscitam processos conflituosos e de exclusões/dominações.

No entanto, reconhecemos a complexidade do tecido social, repleto de contradições pelo fato de que nele estão valores morais não escritos, mas defendidos fervorosamente por determinados grupos, especialmente os religiosos, que dificultam o encaminhamento de mudanças. No entanto, é inegável a importância das leis jurídicas, como forma de criar meios para que as mudanças culturais cheguem, mesmo que na forma da "lei e na marra". 2

Outros direitos alcançados e de discussões férteis aconteceram em conferencias internacionais, como na Conferência de Cario, em 1994, que contou com a participação de 184 países participantes, que reconheceram o tema da reprodução como de direitos humanos. As Conferências de Pequim e Copenhague também reforçaram esta questão, postulando internacionalmente a revisão das legislações que punem o aborto, como é o caso do Brasil, entendida como questão de saúde pública.

${ }^{1} \mathrm{O}$ aumento da violência contra as mulheres sempre existiu, havendo, nessas ultimas década sua intensificação, e que pode ser decorrente da forma como os homens lidam com a emancipação das mulheres, na negativa de sua participação, mas em virtude da dimensão do tema, requer outra pesquisa.

2 Nesse sentido, tema preocupante e alarmante, mesmo não sendo central em nossa pesquisa visto sua enorme dimensão, e por isso não será aqui analisado, é sobre a violência contra as mulheres, esse constante genocídio presenciado cotidianamente e que Piovesam assim se manifesta: "[...] cabe menção à Declaração sobre a Eliminação da Violência contra a Mulher, aprovada pela ONU, em 1993, bem como à Convenção Interamericana para Prevenir, Punir e Erradicar a Violência contra a Mulher ("Convenção de Belém do Pará"), de 1994. Ambas reconhecem que a violência contra a mulher, no âmbito público ou privado, constitui grave violação aos direitos humanos e limita total ou parcialmente o exercício dos demais direitos fundamentais. Definem a violência contra a mulher como "qualquer ação ou conduta, baseada no gênero, que cause morte, dano ou sofrimento físico, sexual ou psicológico ‘a mulher, tanto na esfera pública, como na privada" (artigo 10). Vale dizer, a violência baseada no gênero ocorre quando um ato é dirigido contra uma mulher, porque é mulher, ou quando atos afetam as mulheres de forma desproporcional. Adicionam que a violência baseada no gênero reflete relações de poder historicamente desiguais e assimétricas entre homens e mulheres. (PIOVESAN, 2004, p. 03).

(1) (1) Perspectivas em Diálogo, Naviraí, v. 8, n. 16, p. 273-295, jan./abr. 2021. 
A legislação não contempla os direitos sob a perspectiva de gênero e direitos das mulheres, o que garante interpretações das leis, bem como a reprodução das desigualdades por via institucional, cultural e de legitimação. Dessa forma, houve conquistas, porém há muito a percorrer diante dos problemas diários como violência doméstica, feminicídio ${ }^{1}$, desigualdade salarial, sub-representação política, não ocupação de cargos de poder, etc.

\section{Considerações Finais}

A legislação tem avançado na conquista de direitos para as mulheres, principalmente através de conquistas do movimento feminista e pelas mulheres. Desta maneira podemos percorrer a trajetória do movimento enquanto político, fundamental na conquista de direitos e na manutençao da democracia desde o final do século XIX, inicio do século XX.

As 3 ondas revelam pautas e lutas importantes, como na primeira com o direito do voto e participação na política institucional, na segunda onda direitos reprodutivos, saúde e educação pública, sexualidade, trabalhistas e a formação da base teórica do movimento com estudos desenvolvidos sobre a condição comum de opressão das mulheres: o sexo feminino. Já na terceira a frente na manutenção da democracia, direitos conquistados com a constituição de 1988, a institucionalização e dinamização do movimento, os estudos interseccionais, etc.

Desarte evidenciamos o caráter político desde a origem do movimento feminista, bem como seus avanços, conquistas, lutas, pautas, até os dias atuais. Além disso, também percebemos o quanto ainda é preciso avançar para combater a desigualdade e violências presentes até os dias atuais. Podemos observar ao longo do texto que a desigualdade social produzida pela categoria gênero influência diretamente na posição das mulheres na sociedade e relações sociais, como o afastamento do mundo público e do poder, devido à divisão hierárquica do poder.

Assim, perceber a história e a construção do movimento é fundamental para dar continuidade a essas lutas, percurso, conquistas e importância para toda sociedade. Além disso, seu caráter plural devido as diferentes opressões que aflige os sujeitos de acordo com seu recorte social, atuando em um amplo debate e sendo essencial para democracia.

Perceber os avanços e caminhos, nos mostra a potência transformadora, coletiva do movimento e que ainda há muito a avançar, mas que é possível, pois muito já foi alcançado até aqui, promovidas com as reinvindicações feministas, e introduzidas no Estado através de políticas públicas e direitos.

Compreendemos com isso, o quanto às mulheres lutaram e conquistaram em movimentos externos, tensionado, pressionando, reivindicando e conquistando direitos. Precisamos constantemente unir forças e ocupar todos os espaços, quebrar

1 O feminicidio é um exemplo da continuidade do patriarcado atualmente, onde as mulheres são mortas por seus companheiros e a legislação não os pune severamente. Neste panorama, o M.S. se encontra na $6^{\circ}$ posição dentre os vinte e sete Estados do país com maiores taxas de feminícidios, é o primeiro com a maior taxa de índice de violência doméstica e estupros, segundo dados do Atlas da Violência 2016. Isso significa que não fugimos a regra nacional de violências e extermínios das mulheres e que precisamos estar cientes desta realidade para lidar com o problema e garantir direitos e a vida das mulheres. Não é atoa que o estado foi pioneiro na inauguração da Casa da Mulher Brasileira, instituída por meio do Decreto n. 8.086, de 30 de agosto de 2013, a qual é uma rede ampla de apoio às mulheres vítimas de violência doméstica, desde psicológica ao cuidado das crianças. 
as estruturas do patriarcado, tanto dentro, quanto fora, pois as conexões entre as mulheres têm forças extraordinárias propulsoras de transformações.

Isto nos mostra mulheres em movimento, conscientes da dominação histórica, resistindo e lutando para superação/transformação dessa ordem hierárquica opressora. Assim, visualizamos o caráter político, histórico e cultural do ser mulher e sua participação na transformação social.

\section{REFERÊNCIAS}

ALVES, Bianca. Moreira.; PITANGUY, Jacqueline. O que é o feminismo. Coleção primeiros passos. São Paulo: Editora Brasiliense, 1985.

AVELAR, Lucia. Merces de. Mulher, gênero e política. In: Lucia Avelar; Antonio Octavio Cintra. (Org.). Sistema Político Brasileiro. 3ed. Rio de Janeiro; São Paulo: Konrad Adenauer Stiftung; Editora Unesp, 2015, p. 207-225.

BASTERD, Linhares. Leila; PITANGUY. Jacqueline. O Progresso das Mulheres no Brasil 20032010. Rio de Janeiro: CEPia; Brasília: ONU Mulheres, 1994.

BRASÍLIA, SPM. Biblioteca Virtual em Saúde. Disponível em: I PNPM:

http://bvsms.saude.gov.br/bvc/publicacoes/pnpm_compacta.pdf Acessado em: 24/02/2020.

BUTLER, Judith. Problemas de Gênero: Feminismo e subversão da identidade. Tradução Renato Aguiar. 3. ed. Rio de Janeiro: Civilização Brasileira, 2010.

LOURO, Guacira Lopes. Uma leitura da história da educação sob a perspectiva do gênero. Projeto História. São Paulo, n. 11, p. 31-46, nov. 1994.

MIGUEL, Luis Felipe; BIROLI, Flávia. Feminismo e política: uma introdução. 1. Ed. São Paulo: Boitempo, 2014.

PIMENTEL, Silvia. A mulher e a constituinte. São Paulo: Cortez: EDUC, 1987.

PINTO, Celi Regina. Jardim. Uma história do feminismo no Brasil. São Paulo: Editora Fundação Perseu Abramo, 2003

PIOVESAN, Flavia. A mulher e o debate sobre direitos humanos no Brasil. Revista de Doutrina da 4a Região, n. 2, 24 ago. 2004

PISCITELLI, Adriana. Re-criando a (categoria) mulher. Campinas, 2001.

ROSTELATO, Telma Aparecida. O direito humano de ser mulher: a proteção consagrada pelo código civil pátrio, em observância aos tratados internacionais. Petrópolis, Lex Humana, v. 8, n. 2, p. 137-155, 2016, issn:2175-0947.

SAFFIOTI, Heleieth. A Mulher na Sociedade de Classes: mito e realidade; prefácio de Antônio Cândido de Mello \& Souza. Petrópolis, Vozes, 1976. 